\title{
Evaluating The Effectiveness Of ICT To Support Globally Distributed PBL Teams
}

\author{
Chew Swee Cheng \\ Associate Consultant (PBL)/ Lecturer \\ Temasek Polytechnic IT School \\ 21 Tampines Avenue 1, Singapore 529757 \\ (65) 67805266 \\ Chewsc@tp.edu.sg
}

\author{
Chris Beaumont \\ Senior Lecturer \\ Liverpool Hope University College \\ Hope Park, Liverpool \\ (44) 151-291-3000 \\ Beaumoc@hope.ac.uk
}

\begin{abstract}
In the 21 st century it is becoming increasingly common to work and learn in teams that are globally distributed. Such teams rely heavily on ICT to facilitate communication. There are many communication tools and technologies to choose from. This study investigates the effectiveness of a rich set of tools and considers if synergy exists between them.

This paper reports and analyses the use of communication tools by students in a distributed Problem-based Learning (dPBL) environment. The PBL teams consisted of four students from Singapore and four from the UK. Teams had a rich set of synchronous and asynchronous communication tools available to them, including ISDN videoconference, WebCam video/audio, Microsoft NetMeeting ${ }^{\circledR}$ Chat, Asynchronous drop box and threaded discussion Forum.

This ethnographic study showed that semantic discussion threads included the use of all tools and enabled students to effectively co-construct meaning (and understanding). Students were able to deploy the use of different tools effectively to achieve the learning outcomes intended for various stages in the PBL cycle, with both asynchronous and synchronous media being considered of high importance.
\end{abstract}

\section{Categories and Subject Descriptors}

K.3.1 [Computers and Education]: Computer Uses in Education collaborative learning, distance learning.

K.3.2 [Computer and Information Science Education]: Computer science education

\section{General Terms}

Design, Performance, Human Factors.

\section{Keywords}

Problem-based Learning (PBL), Distributed Problem-based Learning (dPBL)

\footnotetext{
Permission to make digital or hard copies of all or part of this work for personal or classroom use is granted without fee provided that copies are not made or distributed for profit or commercial advantage and that copies bear this notice and the full citation on the first page. To copy otherwise, or republish, to post on servers or to redistribute to lists, requires prior specific permission and/or a fee.

ITICSE'04, June 28-30, 2004, Leeds, United Kingdom.

Copyright 2004 ACM 1-58113-836-9/04/0006...\$5.00.
}

\section{INTRODUCTION}

Globally distributed work teams are becoming more common and the range of tools and technologies to support them is also growing. This raises a number of issues for educators: Which tools are appropriate and how should they be used? How can students develop (employability) skills through experiencing such a distributed environment?

This paper reports on a project to explore and analyze these questions in the context of distributed Problem-based Learning (dPBL).

\section{PROBLEM-BASED LEARNING (PBL)}

PBL is a teaching methodology in which an authentic, real-world problem drives the curriculum [2]. Students work in small groups of about 4 or 5 , solving problems presented to them and which are based on real work scenarios. Professional and funding bodies promote $\mathrm{PBL}$ as an appropriate strategy for professional education and it is increasingly becoming the method of choice[10]. Ellis et al. [4] suggest that "the computing discipline lends itself to PBL". Distributed PBL (dPBL) is a variation of PBL that mirrors the situation of geographically dispersed work teams and therefore provided a very suitable basis for the study.

Successful Problem-based Learning requires effective communication for a variety of different purposes. These include social and team maintenance, problem solving, constructing understanding relating to the PBL case and task/process oriented related to organisational aspects. This communication is particularly challenging in distributed forms of PBL As Clark and Brennan, cited in Preece [11] put it, participants, "....have to coordinate on process, they need to update their common ground moment by moment. All collective actions are built on common ground and its accumulation".

Strategies used to address these issues comprised both synchronous and asynchronous tools. Synchronous tools included ISDN Video conferencing, WebCam video conferencing and synchronous chat (Microsoft NetMeeting/ Messenger). A specialized portal (VLE) provided asynchronous tools. The portal was developed at the Temasek School of IT, specifically to support PBL. Portal features used in this project were the asynchronous threaded discussion Forum, drop-box, peer and self-assessment tools. 
Each PBL team consisted of 4 undergraduate Information Systems students in the UK and 4 HND students in Singapore. The sub-teams of 4 UK and Singapore students held local Face to Face meetings in addition to the use of the other communication media.

The PBL case consisted of a computer network security scenario, involving both theory and practical work. Students were required to identify risks and threats for the scenario and design a secure infrastructure. Both UK and Singapore sides of each team also had to construct logically identical demonstration networks using 5 PCs and associated network software / hardware. The PBL case lasted 6 weeks (including one week for preparation and presentation).

The PBL model used was pitched between one extreme of no specific predefined learning outcomes [8] and the other extreme with clearly defined goals at each stage.[14] This model was adopted taking into consideration the learner characteristics, faculty expectations and institutional requirements.

All students had prior experience of PBL and most had prior experience of both synchronous chat and asynchronous communication facilities through VLEs (e.g. WebCT). However, considerable attention was still given to the preparation of students [15] and [13] 5-step model also informed the module design.

\section{RESEARCH DESIGN}

In this study, the central focus was on how technology enabled participants to collaborate in a dPBL environment. We sought to understand how the participants mediate their learning through the use of the artifacts (that is, the technological tools) present in the environment. The research objectives were to understand:

1. What influences the participants' choice of communication tools in accomplishing the stages of the PBL cycle?

2. How do participants use the different communication tools to achieve collaboration with other members of the PBL team?

The choice of tool was largely under the control of the students, the only constraints being relatively restricted access to ISDN Video conferences. Better understanding of these issues should enable us to construct more effective and integrated communications environments for learning.

The project ran in two action-research cycles. The first cycle (Sept-Oct 2002) provided an opportunity to collect and analyze data for students undertaking the PBL case. The results from this analysis and evaluation were used to inform the second cycle, where a further 16 students undertook a very similar PBL case in September-October 2003. In this second cycle the data analysis tools were refined and some lessons learned were applied to the communication tools.

A naturalistic inquiry (ethnographic) approach was adopted in this study. We deemed this the most suitable approach since we were seeking to understand the process from the participant's viewpoint [7]. The researchers were also tutor-participants in this dPBL environment. Both Qualitative and Quantitative data were collected and analyzed. A combination of these techniques has been used in other studies. Miles and Huberman [9] outlined various reasons for combining the quantitative and qualitative approaches put forth by numerous researchers). In this study, the quantitative data was collected by means of a questionnaire and this served as a preliminary stage to the analysis of the other, rather richer qualitative data. In fact there is something of a tradition of use of qualitative methods in the study of Computer Supported Collaborative Learning (CSCL) [1], [8],[3].

Qualitative data was collected in a variety of forms. The students saved synchronous chat logs and the portal provided a wealth of asynchronous postings, suitably time-stamped. Some ISDN videoconferences were recorded. Students also completed questionnaires and semi-structured interviews, which were videorecorded to enable us to understand their perceptions and motivations for particular actions.

\section{RESULTS AND DISCUSSION}

\subsection{Use of Communication Media}

Students were asked to rate the effectiveness of the available communication tools for each of the PBL activities (Table 1) using a (0-5) point scale. Team maintenance is an integral activity within PBL whereas the other activities constitute distinct stages.

Table 1. PBL activities

Clarification \& Understanding Problem
Identification and prioritization of Learning Issues
Distribution of Learning Issues for research \& Learning
Learning \& research
Sharing of Learning
Application of Learning - solving the problem
Reflection
Team maintenance / social
Peer assessment

For the first batch of students (Sept-Oct 2002), the results are

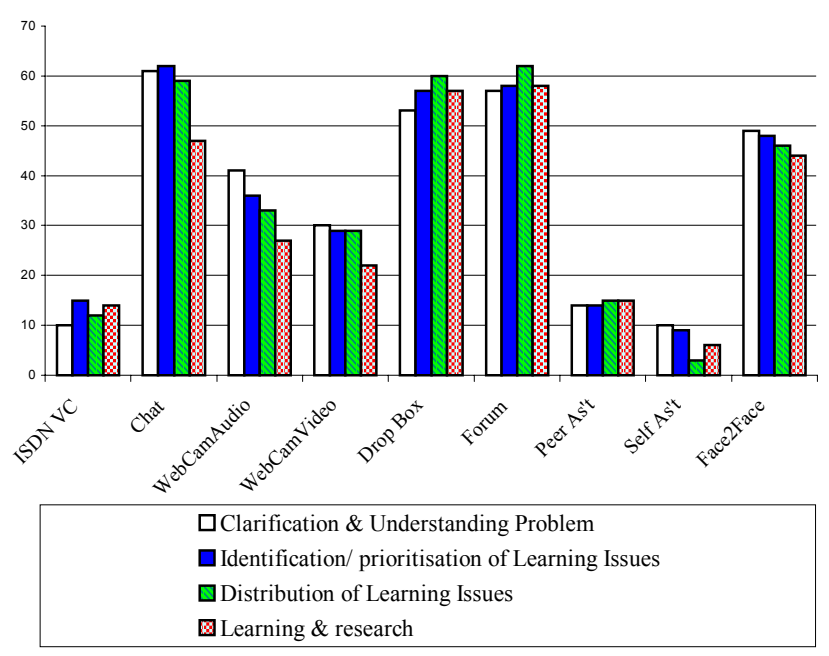

Figure 1. First Cycle: Early PBL stages. 
shown in Figures $1 \& 2$ and have been separated for clarity. The $\mathrm{y}$-axis is a simple aggregation of the responses, with a possible maximum of 75 .

The students rated the Synchronous Chat, Portal Forum and Dropbox as being highly effective for clarifying and understanding the problem statement and identification and prioritization of learning issues with the Chat scoring slightly higher than the Portal Forum and Dropbox.

Students stated that the asynchronous tools offered them an advantage of flexible timing in that they had time to reflect on what had been posted before making their contributions to the discussion.

Students soon rejected the WebCam video, as the quality was poor. Audio was also rejected in favour of chat, since differences in accent between the Singaporean and Liverpool-based UK students impeded understanding.

One important aspect to be pointed out is that the Singapore half and the British half of the PBL teams read the postings and chose to hold face-to-face meetings before posting their contributions, thus effectively reducing the online contributions to 2 sets instead of 8. This is important since one serious problem with asynchronous learning networks is that where the group number is more than $4^{1}$, there is a tendency for information overload, sometimes the messages are even repetitive or irrelevant, causing a lot of frustration. This frustration was indeed reported by one team in the 2003-4 cohort, as they chose to conduct most

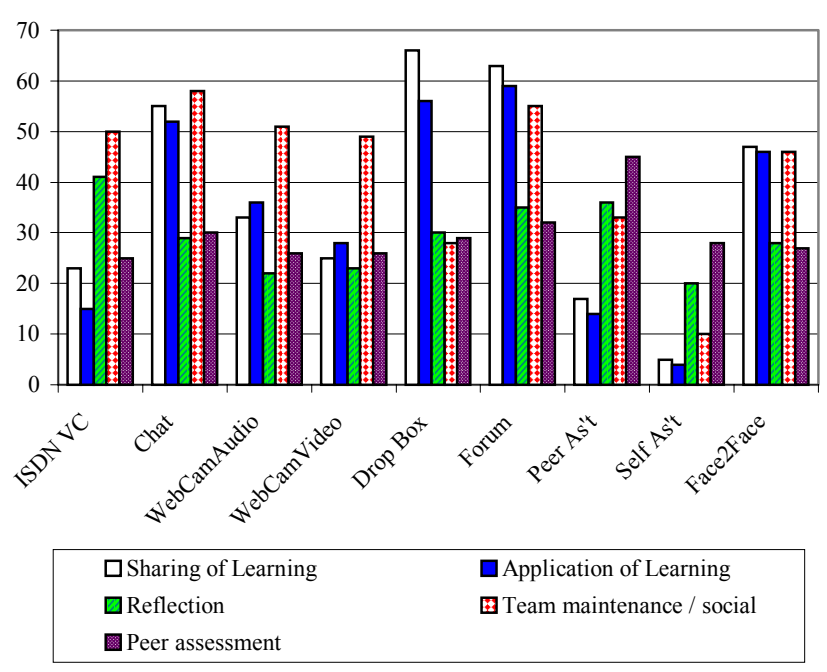

Figure 2. First Cycle: Later PBL stages / Team maintenance.

synchronous chat as individuals from their home locations.

The results in Fig 2 show that in terms of Sharing of Learning and Application of learning, the asynchronous modes, namely the Portal Forum and Dropbox were considered most effective. The

${ }^{1}$ Goodyear reckoned the ideal group size to be four [5]. students used the Forum mainly to inform members about what they had deposited in the Dropbox, clarify issues raised by others or to give additional information about the postings. The work posted was only visible to members of the same team, a trusted environment that ensures the comfort of the contributors.

In terms of reflection, students rate ISDN VC (41), the Peer Assessment Instrument (36) and the Forum (35) as the media that had encouraged them to do self-reflection.

In the second phase (Sept-Oct 2003) the same tools were provided, and three ISDN videoconferences were held successfully at the start (for team orientation / introductions), middle and end (for group reflection) of the PBL case.

The results generally supported those from the first cycle though there were with a number of specific differences:

- The ISDN VC was rated much more highly for all stages except reflection, though still below chat for all stages except reflection.

- $\quad$ The synchronous chat was rated most effective in 7 of the 9 PBL stages. Students scheduled chat sessions at double the frequency of the first cycle. In contrast the Forum and Dropbox were used less often.

- While the students in the first cycle rated the VC most effective for reflection, those in the second cycle rated the self and peer assessment instruments on the portal most effective.

We would suggest that these differences demonstrate the importance of context - in this case demonstrated by the prior experiences of students and the team dynamics as shown below.

The transfer from asynchronous to synchronous communications was unexpected. On further investigation we discovered that the Singapore candidates in the second cycle were less familiar with the Portal than their counterparts in the first cycle. On the other hand they are no strangers to the chat which is a popular form of communication for this age group of students (average age of 20 years in this cycle).

With regard to the use of the ISDN VC for reflection, students in the first cycle experienced one $\mathrm{VC}$ at the end and focussed almost exclusively on reflection. Students in the second cycle used a significant proportion of the VCs to address issues of team dynamics, reducing the relative importance of reflection.

These results from this survey helped the authors sharpen the focus of the research. At the next level of analysis, the question of how exactly did the participants use these media in their collaboration to accomplish their tasks will be examined.

\subsection{Analysis of Discussion Threads}

A Grounded-Theory approach was used for analysis, validation within the context of the project being provided by the four researchers. In the first phase of the project we were able to identify a number of semantic threads of dialogue that students developed which integrated a range of the communication media. These dialogues also displayed distinct milestones [8] and we have established some patterns of use, which lead to some preliminary recommendations. 
Three distinct stages can be identified in students' collaborative efforts.

\subsubsection{Stage 1 Negotiating direction and Goals}

As in any PBL programme, the participants began by negotiating the issues to be investigated. Here they discussed possible versions of the topology, challenged each other's suggestions and clarified their own.

As students explored the learning issues they would like to investigate further, they kept each side updated. They also clarified preliminary issues about equipment given and technical terms used. At this stage, the Forum was used more frequently than the others were since it offered flexibility to the students in terms of taking time to ponder and reflect on an individual and group basis on what had been discussed so far. The Dropbox was used primarily to upload files so that the discussion had some focus for students. It is important to note that the 4 members on each side negotiated their own learning goals and issues and then posted their conclusions in the Dropbox. The discussion between the 2 groups was more focused in the sense that they only needed to refer to 2 possible versions.

Once the goals had been negotiated, it signaled the beginning of the next level of collaboration, the beginning of a period of research and gathering information. Whether the group was able to move on to this higher level of collaboration depended to a large extent on two factors:

1. Whether the members had established a sense of belonging to a learning community which depended on

2. Whether the goals and learning issues had been negotiated by all the members and that they were clear about what each had to do

\subsubsection{Stage 2: Distribution of Work and Individual Research}

At this stage, the use of media shifted from mainly the Forum to the Dropbox as the group members began conducting selfdirected learning, discussing their findings with members from the same country in face to face meetings and posting them in the Dropbox for the other group to comment on.

There were also scheduled synchronous chats. The students used this tool primarily for decision-making and to seek agreement on issues that needed clarification. In one meeting they also used an electronic white board to clarify issues related to the setup of the network system. This took place after a good deal of independent research.

\subsubsection{Stage 3: Preparation of Deliverables for Submission}

At various points of the programme, the programme developers scheduled deliverables for the team to focus on. The team preparation for the submission of this deliverable began in stage two and is completed in stage 3. This occurred at the end of the discussion, after the two sides of the team had made decisions on the final version of the topology diagram during the synchronous chats.

Having a shared goal, in this case, accomplishing the final version of the network topology diagram provided the motivation for the team to move their collaborative process forward. It is important to have such "check points" for students so that both they and the tutors had a feel of the progress made by the team. The team in this study focused on the process of collaboration, evident from the way they went about seeking clarification and agreement from each other. The students' reflective journal entries reinforced the researchers' conclusions that the students had been able to use the communication tools effectively to develop trust, attend to the affective dimension of teamwork, and they could effectively negotiate consensus.

\section{CONCLUSIONS}

In any ethnographic study the validity of the conclusions is heavily dependent on the context and we do not make any strong claims to be able to generalize these. However, we believe that our findings can help others in the design of collaborative environments.

The importance of the rich environment of communication tools became clear in this project, particularly given the global distribution of the teams. This rich set of tools enabled the students to overcome difficulties. For example students regarded synchronous discussion as essential for decision making. However, WebCam video and audio proved ineffective because of bandwidth, latency and language difficulties, though we may expect the technology to improve in the future [6]. Rapanotti [12] also reported benefits from the deployment of voice groupware in a small trial, despite reliability problems.

The students overcame these issues by using Microsoft Messenger ${ }^{\circledR}$ or NetMeeting ${ }^{\circledR}$ chat. They also demonstrated flexibility to arrange meetings to overcome the seven-hour time difference.

Asynchronous Dropbox and Forum facilities were widely used for complementary tasks, such as exchange of information and product delivery (Dropbox) and challenging contributions and constructing shared understanding (Forum).

Our analysis shows that the semantic threads incorporated all of these tools in a rational way, and this emphasizes the need for an integrated set of such tools to encourage the development of highperforming teams.

It is more difficult to draw conclusions regarding the ISDN Video conference. It provided good quality audio and video, but technical difficulties restricted its use to one conference at the end of the first phase. It was also the only tool that was not available 'on-demand'.. In the second phase (Sept-Oct 2003) three videoconferences were scheduled, at the start (for team orientation / introductions), middle and end (for group reflection) of the PBL case. The teams used the middle conference to resolve team conflict and organisational issues.

Differences in results between the two phases suggest that prior experience (and hence preparation) of students is significant in the way they select communication tools.

All the teams involved in this study achieved a high quality solution that incorporated significant input from both UK and Singapore parts of a team. On no occasion did any sub-team withdraw to produce their own solution. They successfully demonstrated interdependence and co-construction of knowledge. Students also achieved the learning outcomes at a high grade. 
Cultural differences caused by international distribution of students were not investigated in any detail within this project, although it emerged as a factor in selecting communication tools.

Further to this investigation, the findings from the micro perspective of the individual and team also prompted the team to analyze the $\mathrm{dPBL}$ programme from a macro perspective, which is the study of the whole programme as three activity systems. The use of Activity Theory helped shed light on how the team functioned in a community and how it had learnt using the mediation tools at its disposal. The findings from this analysis will be presented at a later date.

\section{ACKNOWLEDGMENTS}

We would like to acknowledge the sponsorship and support of the British Council, Temasek Polytechnic and Edge Hill College of Higher Education in making this project possible.

\section{REFERENCES}

[1] Andreassen, E. F. (2000). Evaluating how students organise their work in a collaborative telelearning scenario: An activity theoretical perspective. Masters Thesis. Accessed on 15 June, 2003. http://www.ifi.uib.no/docta/dissertations/andreassen/index.ht $\mathrm{m}$

[2] Boud D, and Feletti, G., Ed. (1997). The Challenge of Problem-based Learning $2^{\text {nd }}$ ed. London, Kogan Page.

[3] Björk, U. (2002), Distributed Problem-based learning in social economy - key issues in students' mastery of a structured method for education. Distance Education, Vol 23, No. 1.

[4] Ellis, A. et al. (1998). Resources, Tools, and Techniques for Problem Based Learning in Computing. ITiCSE '98,3rd Annual Conference on Integrating Technology into Computer Science Education, ACM/SIGCSE. 41-56.

[5] Goodyear, P. (2001) Effective networked learning in higher education: notes and guidelines. Centre for Studies in Advanced Learning Technology, Lancaster University. Accessed on 17 Oct 2003 at http://csalt.lancs.ac.uk/jisc/guidelines_final.doc. p 82
[6] Knutsen, D., Knutson, E., and Slazinski, E. (2003) Employing new advances in IP videoconferencing to enhance teaching and learning through the use of a hybrid distance learning course. Proceedings of the 4th conference on information technology curriculum on Information technology education Lafayette, Indiana, USA . 72 - 75

[7] Koschmann, T. (ed) (1996), CSCL: theory and practice of an emerging paradigm. Malwah, NJ: Lawrence Erlbaum Assoc

[8] McConnell, D. (2002), 'Action research and distributed problem-based learning in continuing professional education'. Distance Education, Vol. 23, No.1.

[9] Miles, M.B. and Huberman, A. M. (1994), Qualitative data analysis, 2nd ed. Thousand Oaks, CA: SAGE Publications. $40-42$

[10] Newman, M. (2003). A pilot systematic review and metaanalysis on the effectiveness of Problem Based Learning, Learning \& Teaching Subject Network Centre for Medicine, Dentistry and Veterinary Medicine (LTSN-01) UK. p5

[11] Preece, J. et al (1994), Human-computer interaction.: The Open University, Addison-Wesley Ltd. Harlow, England p 156

[12] Rapanotti, L., Blake, C. T., and Griffiths, R. (2002) eTutorials with voice groupware: real-time conferencing to support computing students at a distance Proceedings of the 7 th annual conference on Innovation and technology in computer science education, ACM/ SIGCSE Press New York, NY, USA 116-120

[13] Salmon, G (2000) E-Moderating, the key to Teaching and Learning online, London, UK, Kogan Page.

[14] Steinkuehler, C. A., Derry, S. J., Hmelo-Silver, C.E. \& Demarcelle, M. (2002) Cracking the Resource Nut With Distributed Problem-Based Learning in Secondary Teacher Education. Distance Education Vol. 23, Issue 1, 23-39

[15] Woods, D. R. (1995), Problem-based learning: Resources to gain the most from PBL. Hamilton, ON: Don Woods. 